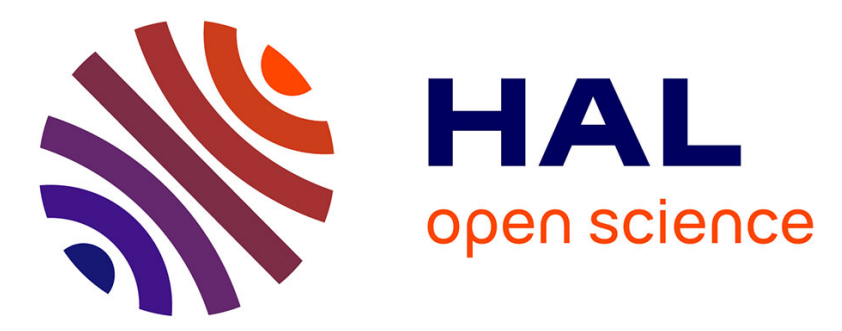

\title{
A spin crossover porous hybrid architecture for potential sensing applications
}

Antoine Tissot, Xavier Kesse, Styliani Giannopoulou, Ingrid Stenger, Laurent Binet, Eric Rivière, Christian Serre

\section{> To cite this version:}

Antoine Tissot, Xavier Kesse, Styliani Giannopoulou, Ingrid Stenger, Laurent Binet, et al.. A spin crossover porous hybrid architecture for potential sensing applications. Chemical Communications, 2019, 55 (2), pp.194-197. 10.1039/C8CC07573E . hal-02305636

\section{HAL Id: hal-02305636 \\ https://hal.science/hal-02305636}

Submitted on 11 Oct 2019

HAL is a multi-disciplinary open access archive for the deposit and dissemination of scientific research documents, whether they are published or not. The documents may come from teaching and research institutions in France or abroad, or from public or private research centers.
L'archive ouverte pluridisciplinaire HAL, est destinée au dépôt et à la diffusion de documents scientifiques de niveau recherche, publiés ou non, émanant des établissements d'enseignement et de recherche français ou étrangers, des laboratoires publics ou privés. 


\title{
A spin crossover porous hybrid architecture for potential sensing applications
}

\author{
Antoine TISSOT ${ }^{\mathrm{a}, \mathrm{b}^{*}}$, Xavier KESSE ${ }^{\mathrm{b}}$, Styliani GIANNOPOULOU, ${ }^{\mathrm{a}}$ Ingrid STENGER ${ }^{\mathrm{c}}$, Laurent BINET ${ }^{\mathrm{d}}$, Eric \\ RIVIERE ${ }^{\mathrm{e}}$, Christian SERRE ${ }^{\mathrm{a}, \mathrm{b}^{*}}$
}

Spin crossover cations have been successfully synthesized in the pores of the mesoporous robust Metal-Organic Framework (MOF) MIL-100(Al) through sequential introduction of Fe(III) cations and sal ${ }_{2}$ trien ligand. The MIL-100(Al)@Fe(sal ${ }_{2}$ trien) hybrid material retains its crystallinity and a partial porosity compared to the parent MOF. The spin state of the $\mathrm{Fe}\left(\mathrm{sal}_{2} \text { trien }\right)^{+}$cations can be modulated at room temperature through sorption of guest molecules, paving the way to the design of new generations of sensors based on MOF@spin crossover complexes solids.

Metal-Organic Frameworks (MOFs) are ideal materials for the modular design of complex assemblies, as they possess a longrange ordered hybrid structure associated with well-organized micro- or mesoporous channels and/or cages. ${ }^{[1]}$ Their chemical composition (metal cation, ligand) can be easily tuned, through direct or post-synthetic methods, as well as the presence of Lewis, redox, photoactive or acid/base Brönsted centers within the framework. This exceptionally large chemical and structural versatility is of great interest for various applications such as gas storage, separation, catalysis, drug delivery, etc. Several MOFs can also be considered for sensing small molecules, mainly through the modulation of their emissive properties. ${ }^{[2]}$ However, in most cases, their limited stability prevents them for being used in real devices. ${ }^{[3]}$

An alternative for the development of new sensing materials would be to take advantage from electronically bi-stable materials such as spin-crossover (SCO) compounds capable of switching their spin states [low-spin (LS) $\leftrightarrow$ high-spin (HS)] upon external stimuli such as temperature, pressure, magnetic field and visible light irradiation. ${ }^{[4]}$ This switching phenomenon is accompanied by change in many physical properties such as color, magnetic susceptibility, thermal/electric conductivity, dielectric constant etc. These features make SCO materials promising candidates for technological applications such as molecular switches and sensors. However, most SCO compounds are not porous and thus lack of selective sorption properties that are required for optimal sensing properties. Thus, porous SCO materials look advantageous as these latter may combine the environmental sensitivity of spin crossover ions with the selective sorption properties of porous solids. To date, Hoffman clathrates are the only family of porous compounds presenting spin transitions close to room temperature. ${ }^{[5]}$ Their potentiality for sensing small molecules such as $\mathrm{CS}_{2}$ or benzene has been evidenced but the sensitivity to other guests remains limited. ${ }^{[6]}$ Coordination frameworks with tetrazole-based linkers have also been developed recently but their limited porosity restricts their application to small gas molecules such as $\mathrm{CO}_{2}{ }^{[7]}$

Taking into account the ability of highly porous MOFs to encapsulate various types of guest molecules, we have focused our attention on the inclusion of spin crossover complexes in the pores of water stable large pores MOFs. This strategy should allow combining the stability and selective sorption properties of the host MOF with the sensing ability of the guest SCO complex. The loading of coordination complexes in the pores of MOFs have been studied within the last years, mainly for catalytic or lighting applications. ${ }^{\left[{ }^{8]}\right.}$ Several strategies can be used, such as the synthesis of the MOF around existing complexes or the in-situ synthesis of the coordination complexes in the pores of a pre-formed MOF.

The encapsulation of spin crossover complexes in MOFs remains however almost unexplored. Bi- and tri-dimensional oxalate-base coordination frameworks containing spin crossover molecular cations have been widely studied, but these materials do not present any permanent porosity. ${ }^{\left[{ }^{9]}\right.}$ Very recently, Abhervé et al. have reported the insertion of Fe(III) 

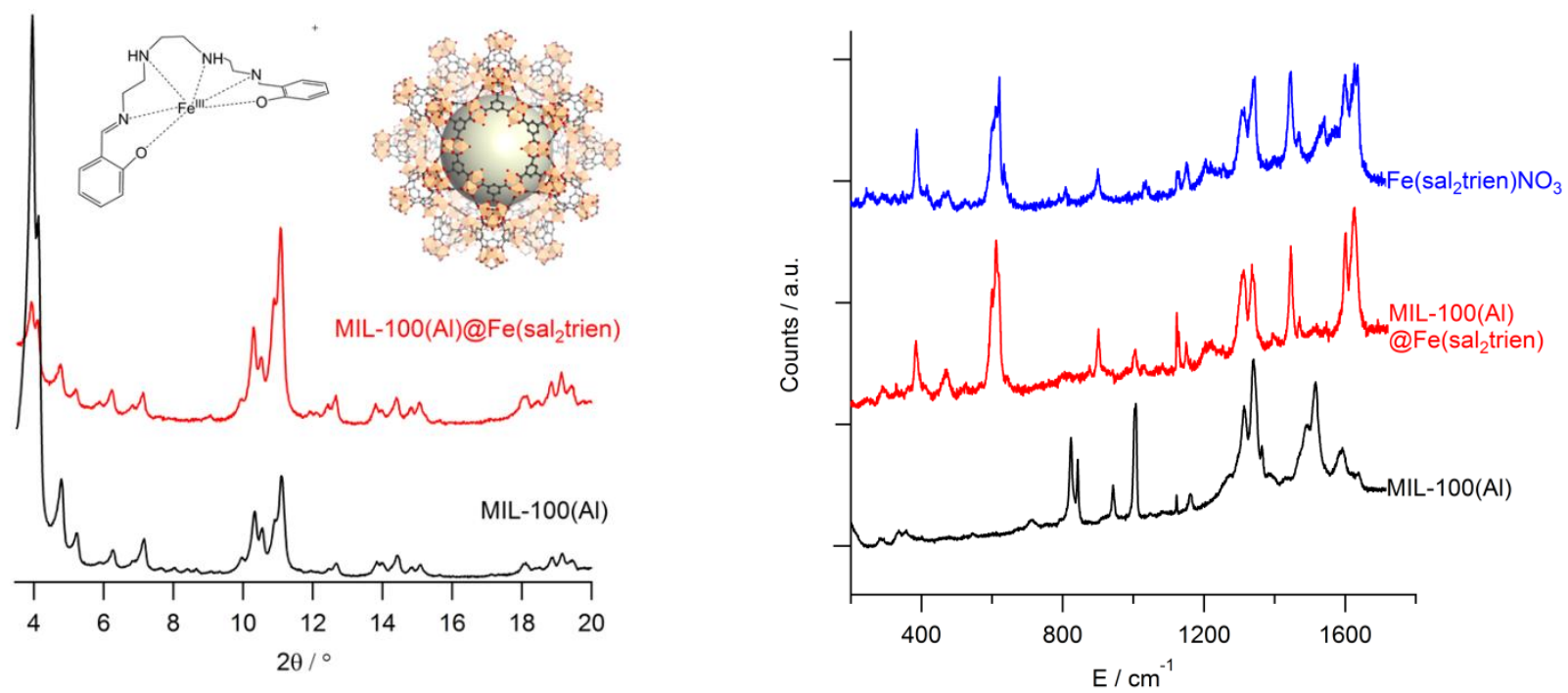

Figure 1: (left) Comparison of the powder X-Ray diffraction patterns of MIL-100(Al) and MIL-100(Al)@Fe(sal ${ }_{2}$ trien), inset: scheme of the $\mathrm{Fe}\left(\mathrm{sal}_{2} \text { trien) }\right)^{+}$complex and structure of the MIL-100(Al) large cage; (right) Comparison of the Raman spectra of MIL-100(Al),

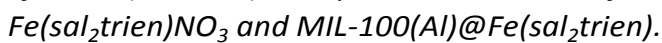

spin crossover cation in the pore of a preformed oxamate network. ${ }^{[10]}$ However, the sorption properties of this solid have not been reported. Janiak et al. have also described the insertion, switching properties and guest sensitivity of an Fe(II) SCO complex in the mesoporous $\mathrm{NH}_{2}-\mathrm{MIL}-101$ (Al) but the water stability of the host MOF remains limited. ${ }^{[11]}$ In addition, as the windows of this MOF are very large (12-16 $⿱$ ) , this is likely that the complex might leach out of the pores when in contact with liquids considering the absence of steric hindrance between the complex and the framework. For this study, MIL-100(Al) (MIL stands for Materials from Institut Lavoisier), a mesoporous diamagnetic $\mathrm{Al}(\mathrm{III})$ tricarboxylate MOF, has then been selected as an host matrix for the following reasons : (i) its remarkable chemical stability (water organic solvents), surpassing by far the one of MIL-101(AI), and (ii) its bimodal pore systems with two sets of mesoporous cages of 24 and $27 \AA$ in order to accommodate the SCO complex but accessible only through 5.5 pentagonal and $8.5 \AA$ hexagonal microporous windows. This is a very suitable material to optimize the concept, as the hexagonal windows are large enough to allow both the diffusion of the metal and ligand sources required to prepare the SCO complex but are much too small to allow any complex leach out of the mesopores. Moreover, the pentagonal windows are too small to allow the diffusion on the ligand, making the associated cages fully accessible for further guest species. Regarding to the spin crossover complex, $\mathrm{Fe}^{\prime \prime \prime}\left(\mathrm{sal}_{2} \text { trien }\right)^{+}$has been selected for its a good stability in solution and its thermal switching in solution close to room temperature. ${ }^{[12]}$

MIL-100(Al) has been prepared as previously described by microwave-assisted synthesis. ${ }^{[13]}$ The $\mathrm{Fe}\left(\mathrm{sal}_{2} \text { trien }\right)^{+}$has been synthesized in the pores of MIL-100(Al) through the "ship-in-abottle" technique. Briefly, we have sequentially inserted first the Fe(III) cation, then the ligand in the pores of the MOF and finally thoroughly washed the solid to remove the complexes formed outside the pores (see Supplementary Information). As mentioned above, the resulting complex in the pores shall remain trapped inside the pores because the windows of the MOF are too small to allow any leaching. As evidenced in Figure 1 , the main characteristic powder X-ray diffraction (PXRD) Bragg peaks of MIL-100(Al) are still observed in the MIL-100(Al)@Fe(sal ${ }_{2}$ trien) hybrid solid, indicating that the crystallinity of the solid is retained during the loading process. The relative intensity of the low-angle peaks decreases in MIL100(Al)@Fe(sal 2 trien), which is consistent with the loading of the coordination complex in the pores of the MOF. ${ }^{[14]}$

The Raman spectrum of the composite material has been measured at room temperature and compared to the one of the parent MOF MIL-100(Al) and of the reference molecular compound $\mathrm{Fe}\left(\mathrm{sal}_{2}\right.$ trien) $\mathrm{NO}_{3}$ (Figure 1). The characteristic peaks of the $\mathrm{Fe}\left(\mathrm{sal}_{2}\right.$ trien) ${ }^{+}$complex are clearly observed in the composite, which confirms that the complex has been successfully synthesized in the pores of the MOF. 

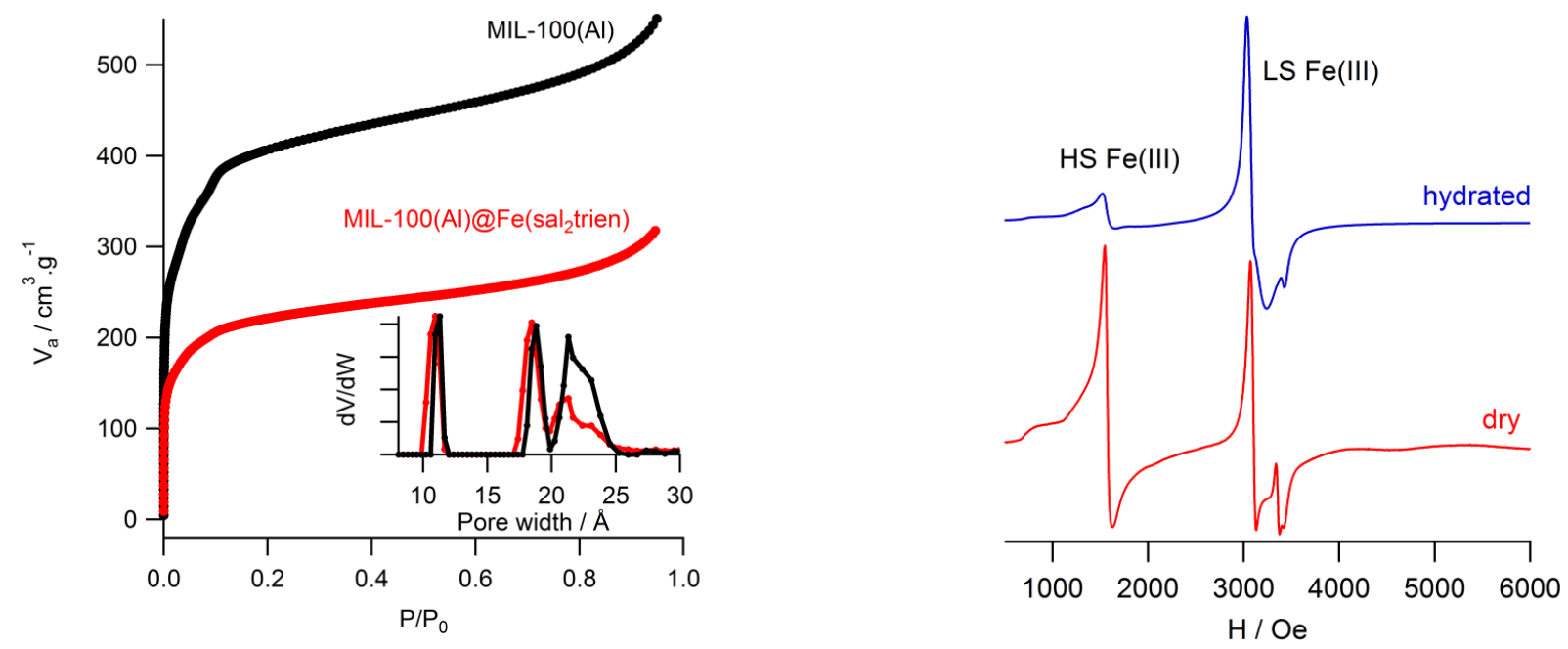

Figure 2: (left) Comparison of the $\mathrm{N}_{2}$ sorption isotherms at $77 \mathrm{~K}$ of $\mathrm{MIL-100(Al)}$ and MIL-100(Al)@Fe(sal ${ }_{2}$ trien) and (inset) pore size distribution obtained by DFT; (right) X-band EPR spectrum of MIL-100(Al)@Fe(sal ${ }_{2}$ trien) recorded at $10 \mathrm{~K}$.

The most intense peaks of MIL-100(Al) are also observed in the composite, but their intensity is significantly lower than the one of the complex, while the opposite trend is observed in the Infrared spectra (see Figure S1 in Supplementary Information). This can be explained by the excitation wavelength used to collect the Raman spectra $(514.5 \mathrm{~nm})$, which selectively excites the iron(III) complex.

Nitrogen sorption experiments have been performed on the solids (see Figure 2). Noteworthy, both the BET surface area $\left(1620 \mathrm{~m}^{2} \cdot \mathrm{g}^{-1}\right)$ and the nitrogen uptake $\left(440 \mathrm{~cm}^{3} \cdot \mathrm{g}^{-1}, \mathrm{P} / \mathrm{P}_{0}=0.6\right)$ of MIL-100(Al) are in line with the previously published results. ${ }^{[13]}$ For the MIL-100(AI)@Fe(sal 2 trien) composite, both values significantly decrease (BET surface area of $840 \mathrm{~m}^{2} . \mathrm{g}^{-1}$, uptake of $250 \mathrm{~cm}^{3} \cdot \mathrm{g}^{-1}$ ), in agreement with the successful preparation of the complexes in the pores of the MOF. This is further confirmed by the pore size distribution obtained by DFT calculations, assuming cylindrical pores and an oxide surface (see inset figure 2), which evidence that only the larger cages of MIL-100(Al) contain SCO complexes. Interestingly, as expected, the intermediate cages remain empty because the pentagonal windows are not large enough to let the ligand diffuse inside these cages. Based on this result and on EDX analysis, the loading can be evaluated to ca. $8 \mathrm{Fe}$ (III) complexes per large cage (see Supporting Information Figure S1).

EPR spectrum has been collected at $10 \mathrm{~K}$ on the composite material (Figure 2 ) in order to characterize the complex inside the MOF. The spectrum of the hydrated compound is characteristic of an LS Fe(III) $(S=1 / 2)$ is a pseudo-axial geometry $\left(\mathrm{g}^{\perp}=2.18\right.$ and $\left.\mathrm{g}^{\prime \prime}=1.96\right)$, which is a further evidence of the presence of $\mathrm{Fe}\left(\mathrm{sal}_{2} \text { trien }\right)^{+}$complexes in the composite material. ${ }^{[15]}$ A signal corresponding to traces of $\mathrm{Fe}(\mathrm{III})$ in the HS state is also detected $(\mathrm{g}=4.28)$. The dehydration of the solid (thermal treatment at $100^{\circ} \mathrm{C}$ under vacuum, see Figure S2) induces important changes in the relative intensities of the LS and HS signals, which indicates that the dehydration induces an increase of the HS fraction in the solid.

The magnetic properties of the MIL-100(Al)@Fe(sal ${ }_{2}$ trien) composite solid have then been investigated (see Figure S3) and compared to the parent $\mathrm{Fe}\left(\mathrm{sal}{ }_{2}\right.$ trien $) \mathrm{NO}_{3}$, which is $\mathrm{LS}$ at every temperature. ${ }^{[16]}$ The observed magnetic susceptibility, either without solvent molecules inside the pores or loaded with ca. 30 wt \% water (see Figure S2 in Supplementary Information), shows a significant difference between the dried and loaded composite: the magnetic susceptibility of MIL100(Al)@Fe(sal ${ }_{2}$ trien) is much higher at every temperature for the dehydrated compound, indicating a larger HS fraction. This observation is in line with the EPR spectra recorded at $10 \mathrm{~K}$. Above room temperature, both hydrated and dehydrated compound start to undergo a gradual thermal spin crossover, which remains incomplete at $350 \mathrm{~K}$. This result evidences how the sorption of water molecules in the pores of the MOF can influence the switching properties of the guest complexes and can be related to the solvent dependence of the spin state of $\mathrm{Fe}\left(\mathrm{sal}_{2} \text { trien }\right)^{+}$in solution at room temperature. Indeed, Wilson et al. have demonstrated that the spin state of the complexes can be correlated to the ability of the solvent to interact through H-bonding. ${ }^{[17]}$ In the MIL-100(Al)@Fe(sal ${ }_{2}$ trien), the water sorption in the pores of the MOF is likely to induce a change in the environment of the $\mathrm{Fe}\left(\mathrm{sal}_{2} \text { trien }\right)^{+}$through the formation of $\mathrm{H}$-bonds between the water molecules and the $\mathrm{NH}$ groups of the $\mathrm{sal}_{2}$ trien ligand, therefore influencing the spin state switching properties of the complex inserted in the pores.

Finally, the evolution of the optical absorption spectrum at room temperature has been monitored (Figure 3 and S4). The spectrum of the dehydrated compound present an absorption band at $510 \mathrm{~nm}$, corresponding to a LMCT transition of the $\mathrm{Fe}\left(\mathrm{sal}_{2}\right.$ trien) ${ }^{+}$in the $\mathrm{HS}$ state, along with a shoulder at $660 \mathrm{~nm}$ that can be attributed to a LMCT transition of the $\mathrm{Fe}\left(\mathrm{sal}_{2} \text { trien }\right)^{+}$ in the LS state. ${ }^{[18]}$ Therefore, the dehydrated MIL100(Al)@Fe(sal 2 trien) compound is mainly HS at room temperature, which is consistent with both EPR and magnetic measurements. Upon water sorption at room temperature, the intensity of the LS absorption band increases at the expense of the HS one, on a timescale of ca. one hour (Figure S4), which evidences that adsorbing water in the pores of the MOF can modulate the spin state of the host complex. This phenomenon is fully reversible on several 
hydration/dehydration cycles, illustrating the good water stability of both the MOF and the guest Fe(III) complex.

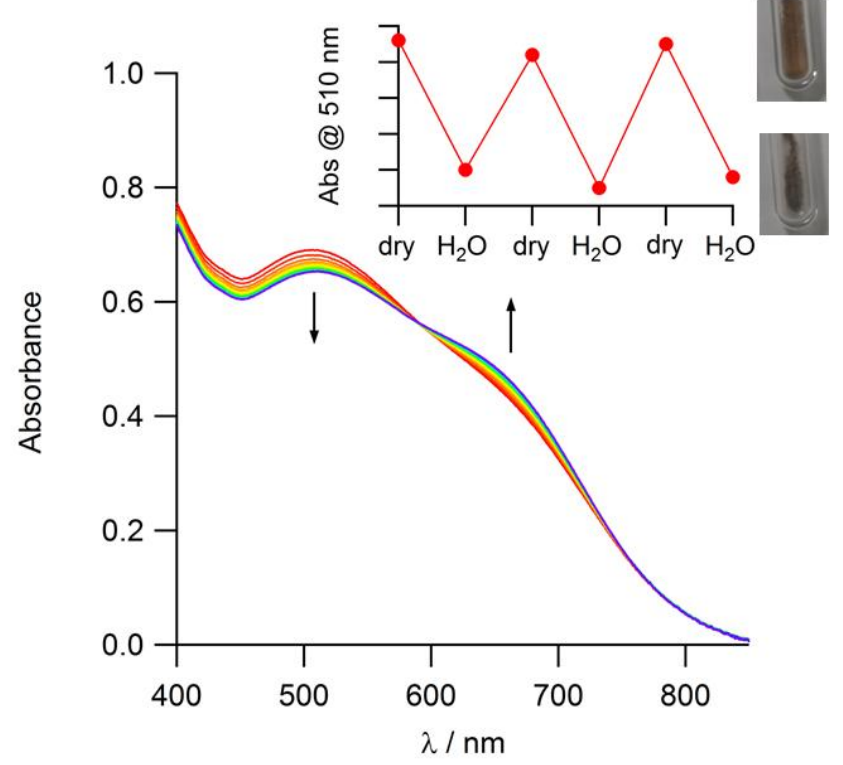

Figure 3: Evolution of the optical absorption spectrum of MIL100(Al)@Fe(sal ${ }_{2}$ trien) upon water sorption; inset: Evolution of the absorption at $510 \mathrm{~nm}$ upon several water sorption/desorption cycles.

In conclusion, we report for the first time a strategy dealing with the trapping, through an in-situ synthesis, of a Fe(III) spin crossover complex into a water stable bimodal pores MOF (MIL-100(AI)). The composite material retains its crystallinity and a partial porosity compared to the parent MOF, while the spin state of the inserted $\mathrm{Fe}^{\prime \prime \prime}\left(\right.$ sal $_{2}$ trien) ${ }^{+}$cations can be modulated at room temperature by water sorption in the pores of the MOF. The impact of the nature of the guest molecules, and well as its sensing selectivity and sensitivity are currently under investigation. Considering the growing number of mesoporous water stable diamagnetic MOFs and the large diversity of SCO complexes, this paves the way for the design of a new generation of sensing devices based on MOF@spin crossover complexes composites.

\section{Conflicts of interest}

There are no conflicts to declare.

\section{Notes and references}

\# The French EPR network IR Renard, FRE CNRS 3443, is acknowledged for allowing access to the EPR facility.

1 "Metal-Organic Frameworks and porous polymers - current and future challenges" special issue, Chem. Soc. Rev., 2017, 46, 3104.

2 a) L. E. Kreno, K. Leong, O. K. Farha, M. Allendorf, R. P. Van Duyne and J. T. Hupp, Chem. Rev., 2012, 112, 1105; b) Z. Hu, B. J. Deibert and J. Li , Chem. Soc. Rev., 2014, 43, 5815.

3 N. C. Burtch, H. Jasuja and K. S. Walton, Chem. Rev., 2014, 114, 10575.
4 "Spin-Crossover in Transition Metal Compounds, I - III": Top. Curr. Chem. 233-235 (Eds.: P. Gutlich, H. A. Goodwin), Springer, Berlin, 2004.

5 V. Niel, J. M. Martinez-Agudo, M. Carmen Munoz, A. B. Gaspar and J. Antonio Real, Inorg. Chem., 2001, 40, 3838.

6 a) M. Ohba, K. Yoneda, G. Agusti, M. C. Munoz, A. B. Gaspar, J. A. Real, M. Yamasaki, H. Ando, Y. Nakao, S. Sakaki and S. Kitagawa., Angew. Chem. Int. Ed. 2009, 48, 4767; b) C. Bartual-Murgui, A. Akou, H. J. Shepherd, G. Molnar, J. A. Real, L. Salmon and A. Bousseksou, Chem. Eur. J. 2013, 19, 15036; c) Z.-P. Ni, J.-L. Liu, M. N. Hoque, W. Liu, J.-Y. Li, Y.-C. Chen and M.-L. Tong, Coord. Chem. Rev., 2017, 335, 28.

7 E. Coronado, M. Giménez-Marqués, G. Mínguez Espallargas, F. Reyand and I. J. Vitórica-Yrezábal, J. Am. Chem. Soc., 2013, 135, 15986.

8 a) B. Nepal and S. Das, Angew. Chem. Int. Ed., 2013, 52, 7224; b) C. Y. Sun, X.-L. Wang, X. Zhang, C. Qin, P. Li, Z.-M. Su, D.-X. Zhu, G.-G. Shan, K.-Z. Shao, H. Wu and J. Li, Nature. Comm., 2013, 4, 2717; c) M. A. Nasalevich, R. Becker, E. V. Ramos-Fernandez, S. Castellanos, S. L. Veber, M. V. Fedin, F. Kapteijn, J. N. H. Reek, J. I. van der Vlugt and J. Gascon, Energy Environ. Sci., 2015, 8, 364.

9 a) R. Sieber, S. Decurtins, H. Stoeckli-Evans, C. Wilson, D. Yufit, J. A. K. Howard, S. C. Capelli and A. Hauser, Chem. Eur. J. 2000, 6, 361; b) M. Clemente-León, E. Coronado, M. López-Jordà, J. C. Waerenborgh, C. Desplanches, H. Wang, J.-F. Létard, A. Hauser and A. Tissot, J. Am. Chem. Soc., 2013, 135, 8655; c) M. Lopez-Jorda, M. GimenezMarques, C. Desplanches, G. Minguez Espallargas, M. ClementeLeon and E. Coronado, Eur. J. Inorg. Chem., 2016, 2187.

10 A. Abhervé, T. Grancha, J. Ferrando-Soria, M. Clemente-Leon, E. Coronado, J. C. Waerenborgh, F. Lloret and Emilio Pardo, Chem. Commun., 2016, 52, 7360

11 T. Zhao, I. Boldog, V. Spasojevic, A. Rotaru, Y. Garcia and C. Janiak, J. Mater. Chem. C, 2016, 4, 6588 .

12 a) M. F. Tweedle and L. J. Wilson, J. Am. Chem. Soc., 1976, 98, 4824; b) M. Nihei, T. Shiga, Y. Maeda and H. Oshio, Coord. Chem. Rev., 2007, 251, 2606.

13 A. García Márquez, A. Demessence, A. Eva Platero-Prats, D. Heurtaux, P. Horcajada, C. Serre, J.-S. Chang, G. Férey, V. A. de la Peña-O'Shea, C. Boissière, D. Grosso and C. Sanchez, Eur. J. Inorg. Chem., 2012, 5165.

14 R. Canioni, C. Roch-Marchal, F. Sécheresse,a P. Horcajada, C. Serre, M. Hardi-Dan, G. Férey, J.-M. Grenèche, F. Lefebvre, J.-S. Chang, Y.-K. Hwang, O. Lebedev, S. Turner and G. Van Tendeloo, J. Mater. Chem., 2011, 21, 1226.

15 I. Nemec, R. Herchel, I. Salitros, Z. Travnicek, J. Moncol, H. Fuess, M. Ruben and W. Linert, Cryst. Eng. Comm., 2012, 14, 7015.

16 E. Sinn, G. Sim, E. V. Dose, M. F. Tweedle, L. J. Wilson, J. Am. Chem. Soc., 1978, 100, 3375.

17 T. Zhu, C.-H. Su, D. Schaeper, B. K. Lemke, L. J. Wilson and K. M. Kadish et al., Inorg. Chem., 1984, 23, 4345.

18 S. Schenker, A. Hauser and R. M. Dyson, Inorg. Chem., 1996, 35, 4676. 